\title{
The economic implications of a health policy
}

By J. S. MARsh, Department of Agricultural Economics and Management, University of Reading, PO Box 237, Whiteknights Road, Reading, RG6 $2 A R$

This title raises a number of important issues which this paper does not attempt to explore. Any adequate response would require some analysis of what is meant by a 'health policy'. Some attempt would need to be made to evaluate the benefits of health, the costs to society of disease and the resource requirements of policies intended to promote health. Such a 'health policy' would need to relate to all aspects of human activity, not simply to explore one or two dimensions such as diet or exercise. An analysis on such a scale would be valuable and should form a background to a wide range of policy decisions. However, this paper discusses a 'health policy' in the much narrower sense of government actions designed to influence what we eat and the effect of this on those who produce our food. Here there exist perplexing issues and possible hazards to the livelihood, if not the life, of those who work in agriculture.

The paper falls into four sections:

(I) an elementary analysis of the impact of assumed changes in dietary habits,

(2) a discussion of policy options by which the government might influence diet,

(3) an attempt to relate this to the economic context within which the industry operates,

(4) a discussion of adjustments in the agricultural sector.

\section{The economics of assumed changes in dietary habits}

Current concern about what we eat is the result of much painstaking scientific work. Sufficient evidence has now been produced to make the layman pause as he fills his mouth with cream or sugar or settles down to many traditional dishes. Of its nature such evidence does not lead to certainties. Much more remains to be discovered and more than one interpretation of known facts is feasible. This paper can make no attempt to arbitrate in such issues. Rather it makes the assumption that reports such as those from the National Advisory Council on Nutrition Education (NACNE) (1983) and the Committee on Medical Aspects of Food Policy (COMA) (1984) will be taken seriously by consumers and will influence government decisions. The advice given by such authorities is carefully hedged by qualifications which seek to make the reader aware of the incompleteness of much of the scientific evidence presented, the diversity of human needs and the dangers of over-sweeping generalization. However, some clear directions for changed eating habits are proposed. The UK citizens as a whole would be more healthy if they ate less fat, increased their consumption of fibre, kept total cholesterol intake to a low level and controlled total food consumption so as to avoid obesity. 
This paper over-simplifies this complex issue by focussing on one of the recommendations of the COMA report and ignoring much of the complex discussion which surrounds it.

The COMA recommendation to reduce fat intake so that it accounted for not more than $35 \%$ of total energy is of particular concern to agriculture. It would represent a reduction of some $18 \%$ of fat consumption. In the UK most fat intake comes from the livestock sector, in meat and dairy products. Sources of fibre, cereals and fruit, for example, are also produced but usually represent a less-intensive use of land and in important sectors (citrus, etc.) are imported.

As a result of agricultural policy, the market which farmers face for most of their products is in part determined by what consumers are prepared to buy and in part by what the State is prepared to pay.

This situation can be represented schematically by Fig. I. The conventions used in this and the following figures are commonly used in Economic discussion. Briefly, quantities are shown on the horizontal axis (e.g. $\left.\mathrm{Oq}_{1}\right)$ and prices on the vertical axis (e.g. $\left.\mathrm{Op}_{1}\right)$. Demand and supply are represented by lines DD and SS respectively. Line II refers to the price at which the government purchases at interventions occur.

Fig. I which, among other simplifications, ignores trade, shows that at DD (their demand curve) consumers will buy $\mathrm{Oq}_{2}$ at price $O \mathrm{p}_{1}$. Producers will sell $O \mathrm{q}_{1}$ at $O \mathrm{p}_{1}$. They are able to do so because government purchases, represented by II, remove the difference $O q_{1}-O q_{2}$ from the market.

If we assume that consumers, on advice about the risks to their health, reduce their food purchases, their demand can now be represented as $D_{1} D_{1}$. The changes which result include an increase in the expenditure which the State needs to make to keep price at $\mathrm{Op}_{1}$, now the whole of the area $\left(\mathrm{Oq}_{1}-\mathrm{Oq}_{3}\right) \times O \mathrm{p}_{1}$. Further, the

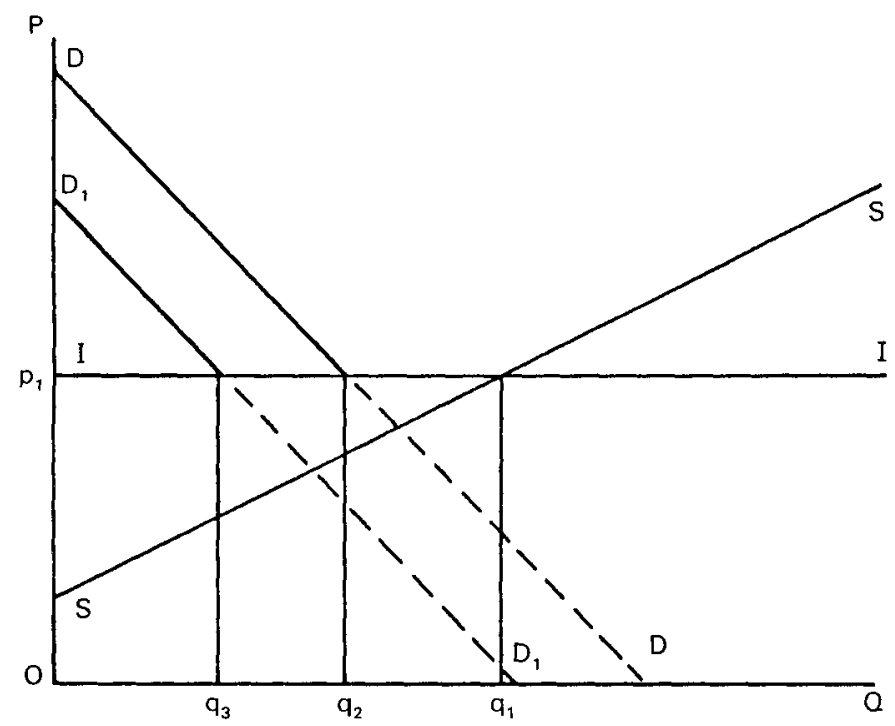

Fig. I. 


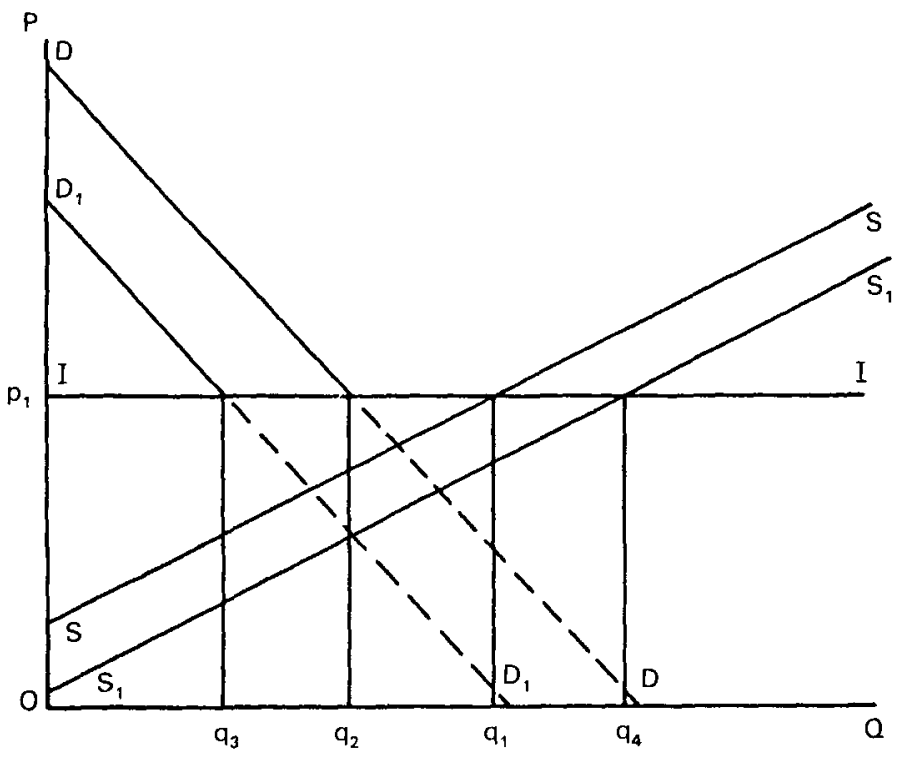

Fig. 2.

satisfaction consumers now derive from the product has fallen, indicated by the difference between the two demand curves.

This is pretty bad news, in economic terms, for consumers and taxpayers, but an additional characteristic of agricultural production in the real world makes it worse. Over time, farming has increased its productivity. At the same price more will be put on the market. Fig. 2 makes the point.

The extra 'dietary cost' which taxpayers have to bear is now increased by the 'productivity cost'; the shift from $O q_{1}$ to $O q_{4}$ in the quantity supplied at $O p_{1}$. Such a conjunction of events, falling demand and rising output, raises severe problems for governments who have to fund the removal of ever-growing volumes of food.

Given this situation, the total cost of the system can be reduced by cutting price or by the imposition of quotas. Fig. 3 shows what happens if price is allowed to fall.

The total taxpayers' cost of support falls from $\left(\mathrm{Oq}_{4}-\mathrm{Oq}_{3}\right) \times O \mathrm{p}_{1}$ to $\left(\mathrm{Oq}_{6}-\mathrm{Oq}_{5}\right)$ $\times \mathrm{Op}_{2}$. At the same time consumers buy more, $\mathrm{Oq}_{5}$ instead of $\mathrm{Oq}_{3}$ and farmers' total revenues fall, by the difference between $\mathrm{Op}_{1} \times \mathrm{Oq}_{4}$ and $\mathrm{Op}_{2} \times \mathrm{Oq}_{6}$. The effect on income will be less since they can escape the costs involved in producing the extra volume between $\mathrm{Oq}_{6}$ and $\mathrm{Oq}_{4}$.

Fig. 4 shows an alternative approach. The imposition of a quantitative limit, equivalent to $\mathrm{Oq}_{7}$, on output. This saves government expenditure equivalent to $\left(\mathrm{Oq}_{4}-\mathrm{Oq}_{7}\right) \times \mathrm{Op}_{1}$. Its effect on total revenue and farm incomes is less than an equivalent reduction achieved by price cuts. It has the important quality, in the context of this paper, that consumers still buy only $\mathrm{Oq}_{3}$. 


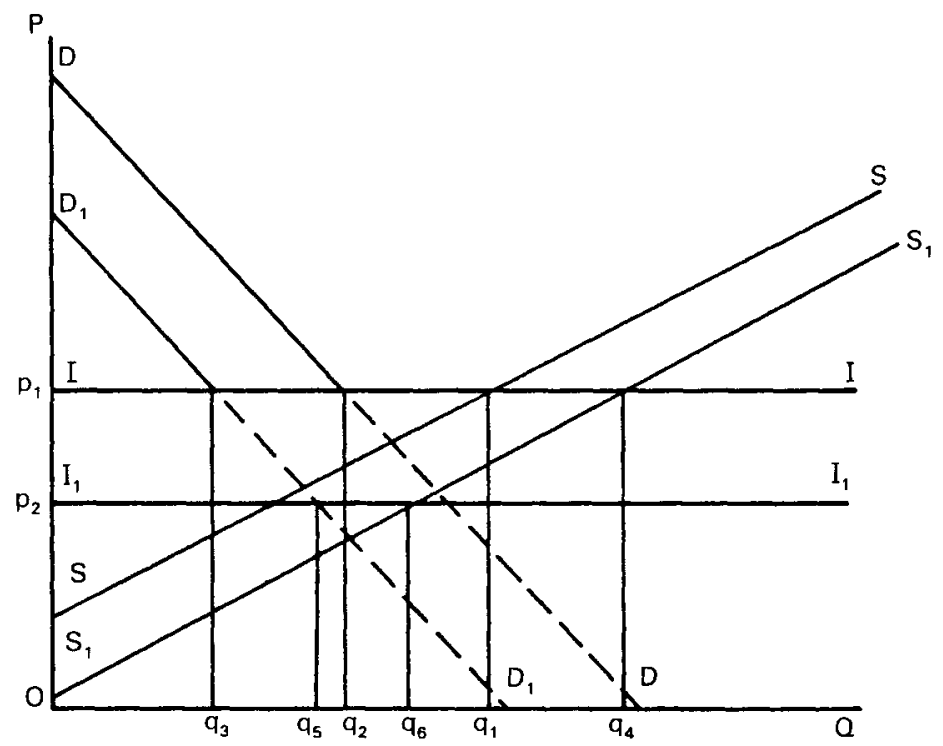

Fig. 3

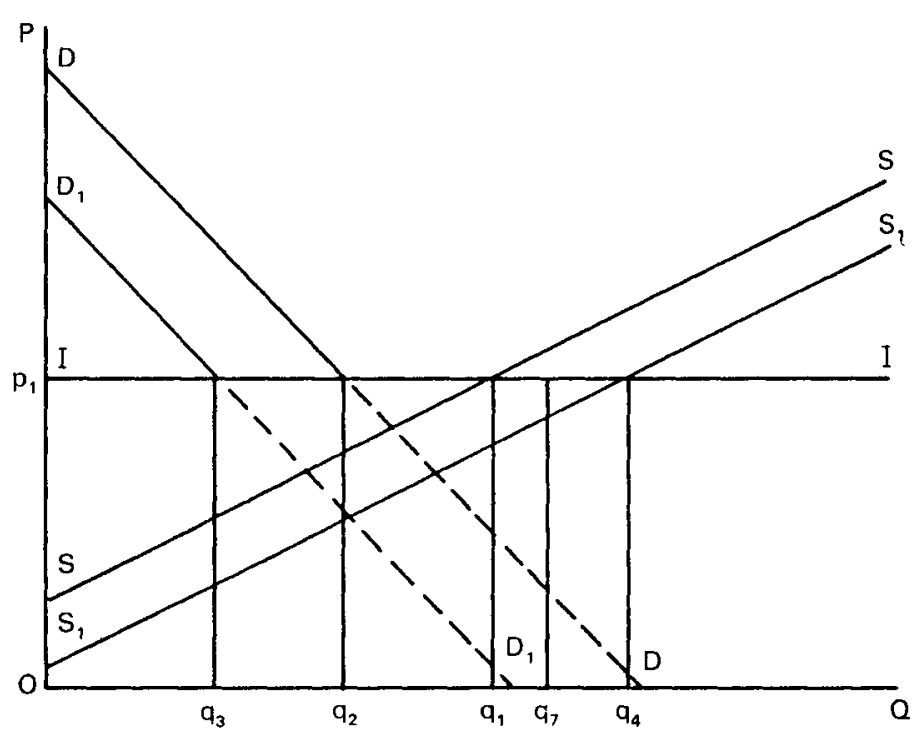

Fig. 4.

The significance of this very schematic approach is to draw attention to two critical implications of the type of advice given by COMA, should consumers respond. It represents a major, new, additional threat to farmers in the UK and the European Community (EC). It threatens to impose a substantial further cost on the already heavily laden EC Budget.

Some equally simplistic arithmetic helps to make the point. Animal products as a group comprise $62 \%$ of UK farm output. Of the arable sector $48 \%$ of output 
comes from cereals, most of which are used to feed animals. If we were to assume that the whole of the recommended cut in fat intake of $18 \%$ was achieved by reducing consumption of animal products and that this was evenly divided among all types of animal product, lost sales, in 1983 terms, would have been $f_{12} 121$ million. If, in a similarly heroic vein of simplicity, we assumed that there was a parallel cut in cereals used for feed, this would mean less sales of home-grown products in that sector of some $\oint_{1} 182$ million. Since some of the feed savings would relate to imported ingredients, a proportionate cut would be worth some fi 55 million, the total effect on farmers would be reduced. Additionally, there would be some savings in breeding stock, buildings, labour, etc. to set against the lower sales. However, in the short term these savings would be hard to realize and in this crude arithmetic are ignored. Other gains could occur as a result of higher sales of fruit and vegetables; say of $£ 90$ million. However, the net result would be a marked reduction in the total revenue of UK farming equivalent to some $f_{\mathrm{I}} 208$ million or $79 \%$ of the 1983 farming income or $30 \%$ of net product.

Such a crude arithmetical approach does not measure the likely impact of a 'health policy' on agriculture. Any attempt to do so would require a much more sophisticated approach, the incorporation of more realistic assumptions about consumer response and more comprehensive information about agriculture. Despite this, it does illustrate that, for an agriculture having the characteristics of farming in the UK, a substantial cut in fat intake achieved by a reduction in sales of livestock and dairy products would have serious consequences.

Translated to an EC scale it is evident that the losses of revenue from consumers which would follow from a serious attempt to implement current dietary guidance would be much larger. Any attempt to offset them would require a major addition to budgetary payments under the Common Agricultural Policy (CAP). The resources of the budget are already and will remain over-stretched as a result of growing productivity. The implication must be that agriculture will be forced to contract.

This gloomy outlook results from the over-simple assumption that consumers will respond to dietary advice by cutting their intake of all animal products equally. Before leaving this economic discussion it is helpful to widen the issues by indicating some of the other 'adjustables' in the system.

First, the industry may seek to throw away those constituents of meat or milk which are under suspicion, to cut off fat, to skim milk, etc. This assumes that people will be prepared to pay more for food to cover the incremental cost of replacing the lost fat and of the processes which removed it. This may well be true and the industry stimulated to produce more rather than less of the raw material livestock.

Second, the food industry might devise ways of producing sanitized versions of traditional foods, removing some ingredients and adding others to ensure the final package is safe. People would spend much the same (or less) on food but a higher share would be absorbed in processing, leaving less for the farmer. 
Third, the agriculture industry might deploy its technical virtuosity to produce leaner meat. Such meat could well be more costly but might sell in a premium market. If this market is substantial many farmers might benefit.

Fourth, even if the products themselves remained unchanged by farmers or processors, consumers might respond by a change in the mix of foods they buy, achieving health, beauty and social acceptability by new combinations of raw and manufactured foods which, in total, appeared to them more healthy. Such a diet might incur less revenue for farmers as a whole, but opportunities for those who could intensify and exploit a new market. It might also be achieved by a switch from some livestock products, e.g. beef and lamb or butter and milk, to others whose fat characteristics were less alarming. As a result some sectors of agriculture might expand whilst others were forced to contract.

\section{Policy options for a more healthy diet}

If governments take seriously the advice they have received, they may attempt to influence eating habits in a 'healthy direction'. Indeed, if public opinion is convinced by such guidance it may press governments to 'take action'. There are at least four different ways in which they might do so: (1) persuasion, (2) taxation, (3) rationing, (4) research and development. Each of these merits some further discussion.

Persuasion, the publication of advice to consumers in readily understood forms, is feasible and not costly. Through the media it may seek to influence all sectors of society. It may stimulate health education in schools and persuade press and television editors to spend more time on the dietary merits of 'approved foods'. It can ensure that foods are labelled in ways which help the concerned consumer to discriminate. It can help to create a climate of demand for 'low-fat, sugar-free' foods which will provide a market for the food firms which will encourage them to invest in the production of such products. Having done so, commercial marketing skills may well be harnessed to changing consumption towards a better diet.

Such persuasive activities are already undertaken by several governments and more seem likely to follow in this direction. Changed labelling rules may raise objections among food processors. Reduced consumption of fats and sugar may cause problems for farmers. No government, however, wishes to be seen to be careless of the population's health. Thus this sort of propaganda seems likely to form an important part of 'health policy' in the next few years.

Consumers do respond to the price of food. Although in formal terms most foods are price inelastic, a substantial cut in price relative to a close substitute does influence the quantity bought. Food prices can be influenced by government policy. For example, the CAP, designed to raise prices to farmers, also forces consumers to pay more for their food. Such price policies have, however, always been based on the need to raise farm revenues, not to discourage consumption. Within the UK, the regressive effect of the CAP, as a tax on food which proportionately is more burdensome for poor consumers than rich, has long been a cause of complaint. 
However, even here a high level of tax on alcohol has often been justified because it discourages consumption.

Abroad there has been less reluctance to tax food by applying value added tax (VAT) to it as to other products. Such a tax has some attraction since it covers a wide spectrum of expenditure, some $15 \%$ of aggregate consumer expenditure in the UK, and since the level of consumption is little affected by modest changes in price, substantial sums can readily be raised. Such regressive effects as it implies could, in principle, be offset by distributing money to people who were poor, through, for example, child allowances, pensions or social-security payments. These features of a tax on food make it a relatively blunt instrument in seeking to influence diet, except where it is heavily discriminatory against certain types of product. As such the CAP may be regarded with favour since it causes dairy products and meat to rise in price relative to vegetable oils, fruits and vegetables. Despite this most governments seem to be unlikely to risk the political consequences of openly imposing higher taxes on food products than on other goods. If they did so, and succeeded in cutting consumption, then they would face too the added problem, in Europe at least, of disposing of even more unsold farm output or coping with the social problems of a considerably accelerated reduction in the agricultural population.

If taxation is difficult, rationing, an attempt by legislative action to limit the quantity of some food or foods consumers may buy, seems unthinkable. Under the hard conditions of war the degree of social discipline needed to impose rationing was accepted, but the existence of 'black markets' demonstrated how hard it was to sustain. Despite this, the UK diet seemed to become more healthy during the war as butter, sugar and meat became scarce.

To impose rationing in peace time would involve many more problems as governments attempted to secure control of supplies: it would also be inefficient. There is immense difficulty in relating individual entitlement to personal need, in ensuring the proper diet for children, pregnant women and adult males. It is virtually impossible, within a family to prevent entitlements being allocated to 'Dad'. If such obvious anomalies are not avoided, any political consensus which accepted social discipline as needful for health would rapidly dissipate. The result would be embarrassment for governments and little real improvement in health.

One of the most powerful engines of agricultural expansion has been the successful pursuit of research and development. Public resources have sought to support the discovery and application of ways of making foods more cheaply. It would be perfectly feasible to seek to stimulate research in directions which gave greater priority to received wisdom about diet. Such research may give rise to substitutes which avoid some problems of traditional products (sweeteners for sugar); to producing improved traditional foods (leaner meat) or to removing undesired characteristics of food whilst leaving the consumer with an attractive product (decaffeinated coffee). Research in these directions may be pursued within the agricultural sector or in the food manufacturing industry. It could be stimulated by matching adjustments in agricultural price policy to encourage the 
use of the new 'safer' products. Unfortunately, many such developments are likely to clash with other goals of farm policy. The deliberate action of the EC in imposing quotas on iso-glucose so as to protect beet-sugar producers conveys a clear warning.

\section{The economic context of the Food and Agricultural Industries}

The present paper has shown that changes in diet associated with a health policy might be expected to have serious economic consequences. Farm incomes would fall, the cost of farm support would tend to grow, consumers would experience some loss of 'economic' welfare and this might be accentuated if governments sought to impose quotas on farmers and high prices on consumers in order both to discourage consumption and aid the farm sector. In reality these changes would take place within a shifting economic environment which would further influence their effect. Some aspects of this economic context must be noted.

The market for agricultural goods is changing significantly. The level of public support for agriculture seems destined to fall in real if not nominal terms. Within the EC, additional resources were only provided after complex negotiations, one outcome of which was an undertaking to control the growth of agricultural spending. Within this total, new demands will have to be met as Spain and Portugal demand support for their own farmers and strengthen the Mediterranean lobby. Such constraints will limit the ability of the CAP to cope with continued increases in farm output in the north or to offset increased production costs as these occur.

Public opinion in the UK is especially critical of agriculture: in part this may reflect dislike of the complex manoeuvres involved in the CAP. More fundamental criticisms attack the ecological, social and aesthetic impact of modern farming practice. Animal welfare lobbyists are more vocal. Recent economic critiques have condemned support for farming. A government wedded to monetarist theory and seeking to curb public expenditure needs little encouragement to retrench. Recent cuts in support for capital investment, in agricultural research and in the provision of advice for farmers demonstrate its attitude more clearly than its words.

Farmers find themselves in possession of assets, and often debts, which have been inflated by past support levels. For many, cutbacks in support will generate real hardship. If, as this paper has assumed, a 'health policy' were to lead to a reduction in consumer demand for livestock products on a significant scale, the number of farmers who would survive the current change in the climate of policy would be substantially reduced.

These adverse trends are occurring in the context of changes in the organization of the market for agricultural goods. At the retail level, the emergence of large-scale retail choices has tilted bargaining power away from farmers and food processors. If 'healthy food' becomes the vogue, these organizations will seek it from whoever is able to supply it. Traditional products may lose their market. Our society includes a growing number of single-person households who may well prefer 'eating out' or 'convenience foods' to traditional diets. Such customers may well 
have less time or patience to cope with food raw materials; so the influence of processors or caterers may grow. Even among family households, greater variety in food is often taken for granted as the preferences of differing members receive recognition. Such flexibility is enhanced by the food processor, the freezer and the microwave.

Such changes in the pattern of demand now take place in an environment of economic stagnation. Aggregate demand is not buoyant. Alternative jobs for people displaced from food industries or farming are scarce. Unemployed, or leisured people, may grow more of their own food. Public expenditure, the almost inevitable result of any policy, is under pressure. As a result, adjustments within the economy tend to be slower and more painful than in more prosperous times.

For the food and agricultural industries, both policy and competition operate at the European and not just the UK level. A nutritional policy which discriminated against UK producers would be ineffective if UK supplies were simply replaced by EC imports. Within the EC there is a shared concern about diet but no consensus as to what its policy should be. There remains, too, a great concern about the rural economy and anxiety about the effect of any change which depresses farmers' incomes.

Such a brief reminder of some features of the economic environment makes it clear that the real freedom of action of the UK government is heavily constrained. In effect, persuasion, directed primarily to consumers and supported by research and development, offers more practical possibilities. Its effects will be slow, will differ among income groups and will probably not lead to the dramatic change in food consumption implied by the expert advice which has been given.

\section{Adjustments in agriculture}

It is evident that agriculture will have to adapt not just to nutritionally motivated changes in demand and policy but to a much more comprehensive set of changes in its economic environment. This final section of the paper looks briefly at some ways in which farming might seek to respond.

A primary aim must be to adapt production to customer requirements. To survive, producers will have to offer a package which is attractive in both price and quality to food processors and mass retailers. Such customers see farm products as an input into their business. They may seek to exploit consumer preferences for food which is low in fat or sugar, etc., and if they succeed will not wish to buy the unwanted ingredient from farmers. Those who produce the low-fat product may receive a premium. Sales of vegetable products may grow. Farmers who continue to produce undesired animal products may face low prices or even no market.

In its present conformation, agricultural policy seems to offer a solution for such producers. They can sell into intervention or, with the aid of subsidy, to third countries. Such an outlet depends on the continued and growing flow of funds through the CAP. Political reasons dictate that this will not be allowed suddenly to collapse. Financial pressures suggest that it will become less and less attractive as a market for farm goods. One way of cutting budget costs would be to reduce 
the intervention price, or disqualify farm intervention products which fell short of some nutritional test. Such an approach could have the paradoxical result of stimulating farmers to produce low-fat products, removing these from the market by intervention or export restitution, and leaving the EC consumer the choice of 'below-quality' fat products.

If neither EC consumers nor the CAP offer a long-term solution to the adjustments facing farmers, attention must turn to the possibility of commercial sales to the rest of the world. Improvements in the productivity of EC agriculture suggest that there is no technical reason why this should not occur. The much more difficult question is economic. High support prices, well above normal world price levels, have allowed high-cost farming to survive in Europe. World markets are residual for many exporters and importers; as such they fluctuate greatly in response to relatively minor shifts in total world production and consumption. The extent to which the EC has frustrated access to its own market has generated opposition among exporters who would be anxious to avoid any loss of market to the EC. Past attempts to organize multilateral commodity agreements have not succeeded. The EC might be better placed to achieve more limited agreements with some Third World countries, but it would then have to give priority to their needs and, in an uncertain world, allow fluctuations in output to influence its internal prices, not cut its exports. Thus, if the EC's farmers are to seek an export outlet as part of their response to declining markets at home, they will need both to produce at lower cost and to tolerate more uncertainty in the prices they receive.

\section{The economics of a 'health policy': some implications}

The present paper has attempted to indicate that the concern expressed in recent expert advice about diet could have very serious consequences for the agricultural and food industries. The scope for introducing a 'health policy' is constrained by political and economic limits which suggest that governments will have to rely upon persuasion to encourage people to eat a 'better' diet. Unfortunately, success in this direction will intensify the already serious adjustment problems facing agriculture. Farmers will need to respond in ways which lead both to higher quality and lower cost. If they succeed, exports may help to relieve pressure on domestic markets and policies. To do so will require the ability to survive a less-certain as well as a lower-priced market.

\section{REFERENCES}

Committee on Medical Aspects of Food Policy (1984). Diet and Cardiovascular Disease. Report on Health and Social Subjects no. 28. London: H.M. Stationery Office.

National Advisory Committee on Nutrition Education (1983). A Discussion Paper on Proposals for Nutrition Guidelines for Health Education in Britain. London: Health Education Council. 